\title{
DESIGN AND IMPLEMENTATION OF ANALOG MULTIPLIER WITH IMPROVED LINEARITY
}

\author{
Nandini A.S ${ }^{1}$, Sowmya Madhavan ${ }^{2}$ and Dr Chirag Sharma ${ }^{3}$ \\ ${ }^{1}$ Department of Electronics and Communication Engineering, Nitte Meenakshi Institute \\ of Technology, Yelahanka, Bangalore- 560064 \\ nandini.sreenivaserediffmail.com \\ ${ }^{2}$ Department of Electronics and Communication Engineering, Nitte Meenakshi Institute \\ of Technology, Yelahanka, Bangalore- 560064 \\ shuba.sow2004@gmail.com \\ ${ }^{3}$ Department of Electronics and Communication Engineering, Nitte Meenakshi Institute \\ of Technology, Yelahanka, Bangalore- 560064 \\ chirag.nmit@gmail.com
}

\begin{abstract}
Analog multipliers are used for frequency conversion and are critical components in modern radio frequency $(R F)$ systems. $R F$ systems must process analog signals with a wide dynamic range at high frequencies. A mixer converts $R F$ power at one frequency into power at another frequency to make signal processing easier and also inexpensive. A fundamental reason for frequency conversion is to allow amplification of the received signal at a frequency other than the $R F$, or the audio, frequency. This paper deals with two such multipliers using MOSFETs which can be used in communication systems. They were designed and implemented using 0.5 micron CMOS process. The two multipliers were characterized for power consumption, linearity, noise and harmonic distortion. The initial circuit simulated is a basic Gilbert cell whose gain is fairly high but shows more power consumption and high total harmonic distortion. Our paper aims in reducing both power consumption and total harmonic distortion. The second multiplier is a new architecture that consumes 43.07 percent less power and shows 22.69 percent less total harmonic distortion when compared to the basic Gilbert cell. The common centroid layouts of both the circuits have also been developed.
\end{abstract}

\section{KEYWORDS}

Multiplier, Gilbert cell, Noise spectral density, Total Harmonic Distortion, Transconductance

\section{INTRODUCTION}

An Analog multiplier is a device having two input ports and an output port. The signal at the output is the product of the two input signals. If both input and output signals are voltages, the transfer characteristic is the product of the two voltages divided by a scaling factor, $\mathrm{K}$, which has the dimension of voltage as shown in Figure 1 [1].

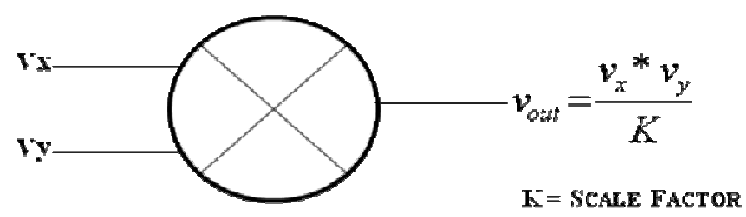

Figure 1. Basic Analog multiplier 
Mixer is a device used to mix two input signals and deliver an output voltage at frequencies equal to the difference or sum of the input frequencies. Any nonlinear device can do the job of mixing or modulation, but it often needs a frequency selection network which is normally composed as a LC network. Hence a mixer needs at least one non-linearity, such as multiplication or squaring, in its transfer function. Every analog multiplier can effectively used as a mixer, but the inverse does not hold [2].

There is a lot of similarity between multiplier and mixer, but the main difference between them is that in frequency multiplier only one signal is implied while in mixer we need two signals as source. The similarity is that, in both of them, we drive circuits to nonlinear region to produce the harmonic of input signal in multiplier and to produce the intermodulation of input signals in mixer. That is, in a mixer, there is a sum and difference of the input frequencies due to the nonlinearity of a device.

\section{MiXer Definitions}

Mixers are non-linear devices used in systems to translate one frequency to another. All mixer types work on the principle that a large Local Oscillator (LO) RF drive will cause switching/modulating the incoming Radio Frequency (RF) to the Intermediate Frequency (IF) [3]. The multiplication process begins by taking two signals:

$\mathrm{a}=\mathrm{A} \sin \left(\omega_{1} \cdot t+\varphi_{1}\right)$ and signal $\mathrm{b}=\mathrm{B} \sin \left(\omega_{2} \cdot \mathrm{t}+\varphi_{2}\right)$

The resulting multiplied signal will be:

$a \cdot b=A B \sin \left(\omega_{1} \cdot t+\varphi_{1}\right) \cdot \sin \left(\omega_{2} \cdot t+\varphi_{2}\right)$

This can be multiplied out thus:

Using the trigonometric identity

$\sin \mathrm{A} \sin \mathrm{B}=-1 / 2[\cos (\mathrm{A}+\mathrm{B})-\cos (\mathrm{A}-\mathrm{B})]$

Where $\mathrm{A}=\left(\omega_{1} \cdot \mathrm{t}+\varphi_{1}\right)$ and $\mathrm{B}=\left(\omega_{2} \cdot \mathrm{t}+\varphi_{2}\right)$

$$
\begin{gathered}
=-\mathrm{AB} / 2\left[\cos \left(\left(\omega_{1} \cdot \mathrm{t}+\varphi_{1}\right)+\left(\omega_{2} \cdot \mathrm{t}+\varphi_{2}\right)\right)\right. \\
\left.-\cos \left(\left(\omega_{1} \cdot \mathrm{t}+\varphi_{1}\right)-\left(\omega_{2} \cdot \mathrm{t}+\varphi_{2}\right)\right)\right] \\
=-\mathrm{AB} / 2\left[\cos \left(\left(\omega_{1}+\omega_{2}\right) \mathrm{t}+\left(\varphi_{1}+\varphi_{2}\right)\right)\right. \\
\left.-\cos \left(\left(\omega_{1}-\varphi_{1}\right) \mathrm{t}-\left(\varphi_{1}-\varphi_{2}\right)\right)\right]
\end{gathered}
$$

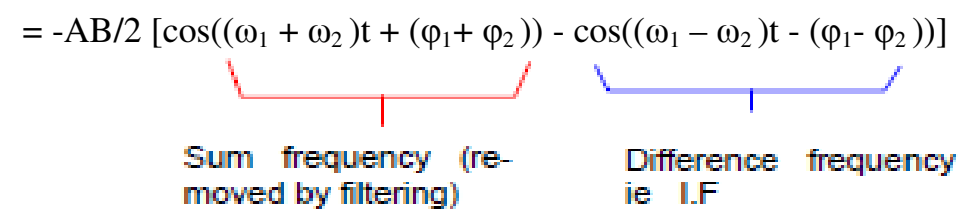

The following parameters are important for an analog multiplier.

(1) Conversion Gain: This is the ratio in $\mathrm{dB}$ between the IF signal which is the difference frequency between the RF and LO signals and the RF signal.

(2) Noise Figure: Noise figure is defined as the ratio of SNR(Signal to Noise Ratio) at the IF port to the SNR of the RF port. 


\section{Gilbert Cell MiXer}

The basic idea of multiplier implementation is illustrated in Figure 2 [4]. Two signals $V_{1}(t)$ and $\mathrm{V}_{2}(\mathrm{t})$ are applied to a non linear device, which can be characterized by a higher order polynomial function. This polynomial function generates the terms like $\mathrm{V}_{1}{ }^{2}(\mathrm{t}), \mathrm{V}_{2}{ }^{2}(\mathrm{t}), \mathrm{V}_{1}{ }^{3}(\mathrm{t}), \mathrm{V}_{2}{ }^{3}(\mathrm{t}), \mathrm{V}_{1^{2}}$ $(\mathrm{t}) * \mathrm{~V}_{2}(\mathrm{t})$ and many others besides the desired $\mathrm{V}_{1}(\mathrm{t}) \cdot \mathrm{V}_{2}(\mathrm{t})$. Then it is required to cancel the undesired components. This is accomplished by a cancellation circuit configuration.

A multiplier could be realized using programmable transconductance components. Consider the conceptual transconductance amplifier of Figure 3(a), where the output current is simply given by

$$
\mathrm{i}_{0}=\mathrm{G}_{\mathrm{m} 1} \mathrm{v}_{1}
$$

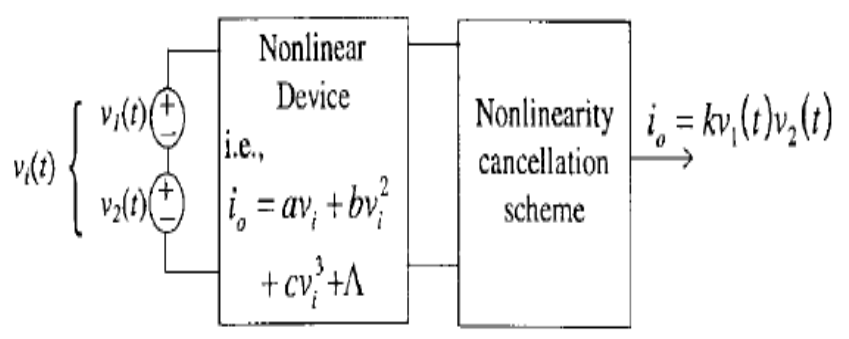

Figure 2. Basic idea of multiplier.

where

$$
\mathrm{G}_{\mathrm{m} 1=} \mathrm{G}_{\mathrm{m} 1}\left(\mathrm{I}_{\text {bias } 1}\right)
$$

For a bipolar transconductor, $\mathrm{G}_{\mathrm{m} 1}$ becomes

$$
\mathrm{G}_{\mathrm{m} 1=} \mathrm{I}_{\text {bias } 1} /\left(2 . \mathrm{V}_{\mathrm{t}}\right)
$$

Where $\mathrm{V}_{\mathrm{t}}$ is the thermal voltage (kT/q).

Next, a small signal is added to the bias current as shown in Figure 3(b). The second input signal $\mathrm{v}_{2}(\mathrm{t})$ can be converted into a current, $\mathrm{i}_{2}(\mathrm{t})=\mathrm{Gm}_{2} \mathrm{v}_{2}(\mathrm{t})$, as illustrated in Figure 3(c).

Then, the output current yields

$$
\begin{aligned}
\mathrm{i}_{0}(\mathrm{t}) & =\mathrm{G}_{\mathrm{m} 1} \mathrm{v}_{1}=\frac{I_{\text {bias } 1}+G_{m 2} v_{2}(t)}{2 v_{t}} \cdot \mathrm{V}_{1}(\mathrm{t}) \\
\mathrm{i}_{0}(\mathrm{t}) & =\frac{G_{m 2} v_{1}(t) v_{2}(t)}{2 v_{t}}+\frac{I_{\text {bias } 1}}{2 v_{t}} v_{1}(t) \\
& =\frac{I_{\text {bias } 2} v_{1}(t) v_{2}(t)}{2 v_{t} \cdot 2 v_{t}}+\frac{I_{\text {bias } 1} v_{1}(t)}{2 v_{t}}
\end{aligned}
$$

or

$$
\mathrm{i}_{0}(\mathrm{t})=k_{1} v_{1}(t) v_{2}(t)+k_{2} v_{1}(t)
$$

Thus, $\mathrm{i}_{0}(\mathrm{t})$ represents the multiplication of two signals $\mathrm{v}_{1}(\mathrm{t})$ and $\mathrm{v}_{2}(\mathrm{t})$ and an unwanted component $\mathrm{k}_{2} \mathrm{v}_{1}(\mathrm{t})$ [4]. This component can be eliminated as shown in Figure 3(d). Better cancellation is achieved when the third transconductor $\left(\mathrm{Gm}_{2}\right)$ becomes a fully differential transconductor, and $\mathrm{v}_{1}$ and $\mathrm{v}_{2}$ are fully differential inputs as illustrated in Figure 3(e).

$$
\mathrm{i}_{0}(\mathrm{t})=2 k_{1} v_{1}(t) v_{2}(t)
$$


This is the basic operation principle of a Gilbert cell [5], [6]. Operational transconductance amplifier (OTA)-based implementations are reported in [8]-[9]. The connection to the Gilbert cell can be seen by substituting the transconductors in Figure 3(e) by bipolar junction transistor (BJT) differential pairs.

As the digital technology dominates in modern electronics, analog circuits are required to share the same standard CMOS process for low-cost fabrication. Thus, the popular BJT Gilbert Cell is not suitable in a standard digital process, and designers must address low power supply voltage requirements. One problem that circuit designers often encounter is how to select the best multiplier architecture for their applications. Unfortunately, designers who propose multipliers in the literature often do not make reference to or comparison to other multipliers. This lack of comparison causes the same basic multiplier architectures to be, from time to time, reported as "new" architectures. The transconductance multipliers are classified into eight types. They can be categorized into two groups based on its MOS operating region, linear and saturation. It should be emphasized that the fundamental multiplier circuit topology for many of the multipliers is the same [4].

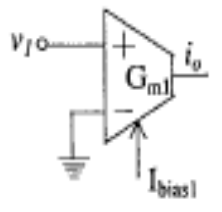

(a)

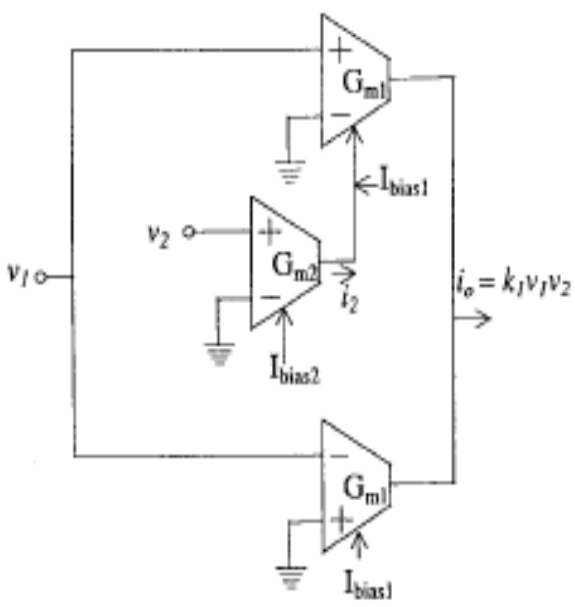

(d)

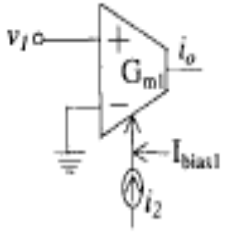

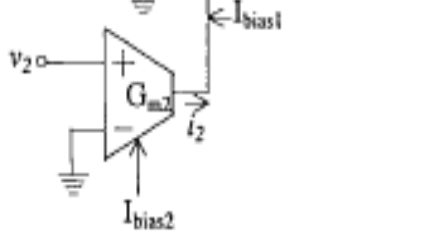

(c)

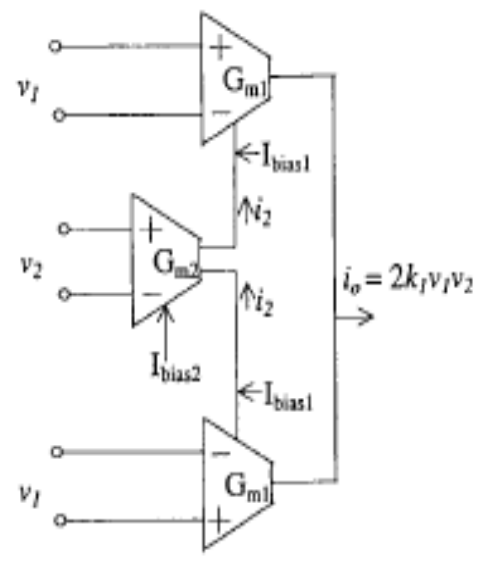

(e)

Figure 3. Multiplication operation using programmable transconductor

\section{Circuit Topologies}

Differential pairs reveals two important aspects of their operations: (1) the small - signal gain of the circuit is a function of the tail current and (2) the two transistors in a differential pair provides a simple means of steering the tail current to one of two destinations. By combining these two properties, we can develop a versatile building block. 
Suppose we wish to construct a differential pair whose gain is varied by a control voltage. This can be accomplished as depicted in Figure 4(a), where the control voltage defines the tail current and hence the gain. In this topology, the voltage gain varies from zero to a maximum value given by voltage headroom limitations and device dimensions. This circuit is a simple example of a "variable - gain amplifier" (VGA) [10]. VGAs find application in systems where the signal amplitude may experience large variations and hence requires inverse changes in the gain.

Now suppose we seek an amplifier whose gain can be continuously varied from a negative value to a positive value. For that we consider two differential pairs that amplify the input by opposite gains Figure 4(b). We now have

$$
\text { and } \quad \begin{aligned}
\text { Vout }_{1} / \text { Vin } & =-\mathrm{g}_{\mathrm{m}} R_{\mathrm{D}} \\
\text { Vout } & / \text { Vin }=+\mathrm{g}_{\mathrm{m}} R_{\mathrm{D}}
\end{aligned}
$$

where $g_{m}$ denotes the transconductance of each transistor in equilibrium. If $I_{1}$ and $I_{2}$ vary in opposite directions, then we have two gain values $\left|v_{\text {out } 1} / v_{\text {in }}\right|$ and $\left|v_{\text {out } 2} / v_{\text {in }}\right|$ which vary in opposite directions.

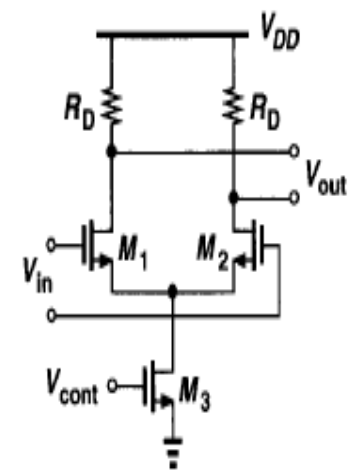

(a)

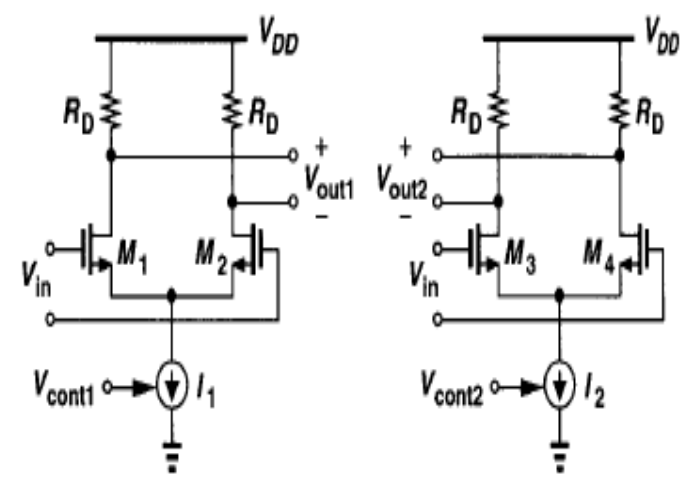

(b)

Figure 4. (a) Simple VGA. (b) two stages providing opposite gains.

We can combine Vout ${ }_{1}$ and Vout 2 into a single output as shown in Fig 5(a) then the two voltages can be summed, producing

$$
\text { Vout }=\text { Vout }_{1}+\text { Vout }_{2}=A_{1} \cdot V_{\text {in }}+A_{2} \cdot V_{\text {in }}
$$

Where $\mathrm{A}_{1}$ and $\mathrm{A}_{2}$ are controlled by $\mathrm{V}_{\text {cont1 }}$ and $\mathrm{V}_{\text {cont2 }}$ respectively.

Since

$$
\begin{aligned}
& V_{\text {out } 1}=R_{D} I_{D 1}-R_{D} I_{D 2} \\
& V_{\text {out } 2}=R_{D} I_{D 4}-R_{D} I_{D 3}
\end{aligned}
$$

We have,

$$
V_{\text {out } 1}+V_{\text {out } 2}=R_{D}\left(I_{D 1}+I_{D 4}\right)-R_{D}\left(I_{D 2}+I_{D 3}\right) .
$$

Thus, rather than add Vout 1 and Vout 2 , we can short the corresponding drain terminals to sum the currents and subsequently generate the output voltage. If $I_{1}=0$ then Vout $=g_{m} R_{D}$ Vin and if $I_{2}=0$, then Vout $=-g_{m} R_{D}$ Vin. For $I_{1}=I_{2}$ the gain drops to zero. In the circuit of Figure 5(b), $V_{\text {cont } 1}$ and $V_{\text {cont2 }}$ must vary $I_{1}$ and $I_{2}$ in opposite directions such that the gain of the amplifier changes monotonically [10]. For a large $\left|v_{\text {cont } 1}-v_{\text {cont } 2}\right|$ all of the tail current is steered to one of 


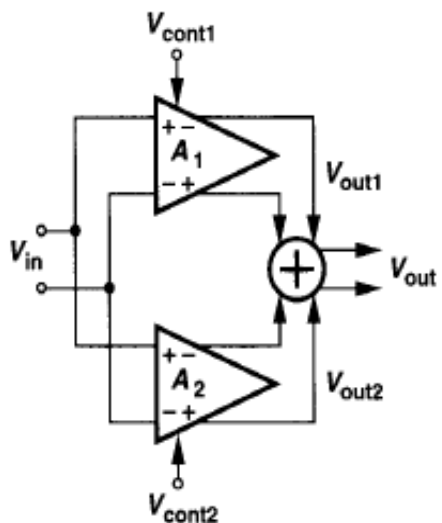

(a)

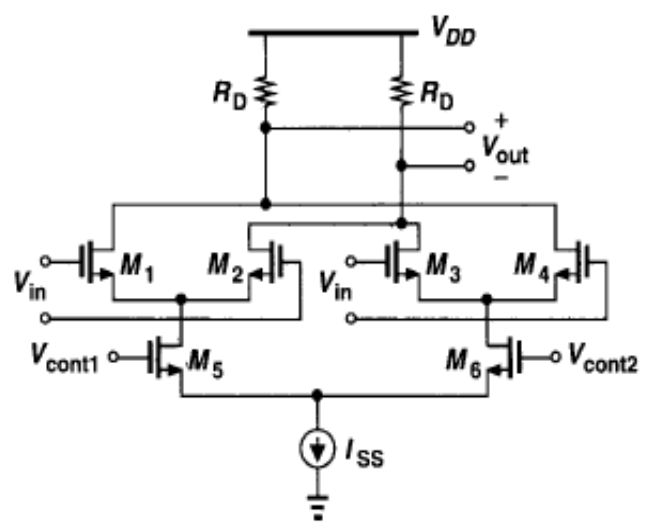

(c)

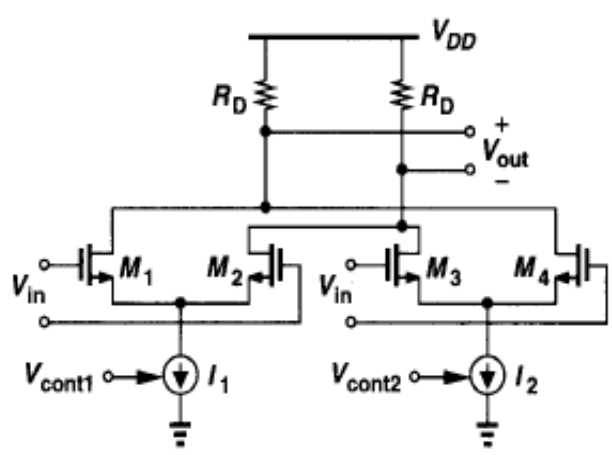

(b)

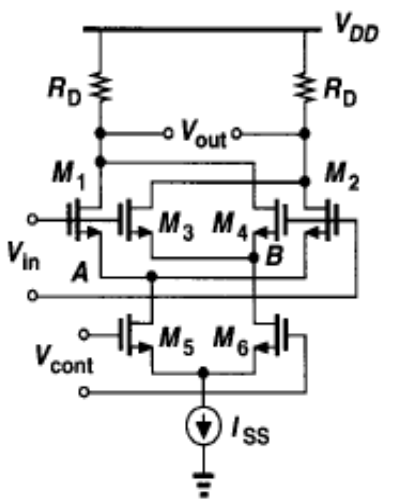

(d)

Figure 5. (a) Summation of the output voltages of two amplifiers, (b) summation in the current domain, (c) use of M5- M6 to control the gain, (d) Gilbert cell

the top differential pairs and the gain from Vin to Vout is at its most positive or most negative value. For Vcont ${ }_{1}=V_{\text {cont }}$, the gain is zero. For simplicity, we redraw the circuit as shown in Fig 5(d) which is called as "Gilbert cell". The idea is to convert the input voltage to current by means of M5 and M6 and route the current through M1 -M4 to the output nodes. If the voltage given to $\mathrm{M} 1$ and $\mathrm{M} 3$ is positive, then only M1 and M2 are on.

$$
V_{\text {out }}=g_{m 5,6} R_{D} V_{\text {in }}
$$

Similarly if the voltage given to M4 and M2 is negative then only M3 and M4 are on.

$$
V_{\text {out }}=-g_{m 5,6} R_{D} V_{\text {in }}
$$

Table 1. Specifications for Multiplier Design

\begin{tabular}{|l|l|ll|}
\hline $\mathrm{V}_{\mathrm{DD}}=5 \mathrm{~V}$ & $\begin{array}{l}\text { Noise spectral } \\
\text { density }<1 \mu \mathrm{V} / \mathrm{Rt}\end{array}$ & $\begin{array}{l}\text { Conversion } \\
>10 \mathrm{~dB}\end{array}$ & gain \\
\hline Power $<1 \mathrm{~mW}$ & $\begin{array}{l}\text { Frequency } \\
\text { operation } \\
>100 \mathrm{MHz}\end{array}$ & $\begin{array}{l}\text { Dynamic } \\
>100 \mathrm{~dB}\end{array}$ & Range \\
\hline
\end{tabular}


International Journal of VLSI design \& Communication Systems (VLSICS) Vol.3, No.5, October 2012

The Gilbert cell shown in Figure 6 includes two resistive loads and eight NMOS transistors, where all are working in saturation region. There are two differential inputs given to the circuit. Input in 1 and in 2 is a differential square signal and in 3 and in 4 is a differential sine signal. The current source provides current to bias the circuit and in this top most four transistor works as switch, the signal fed in the lower part of the circuit is multiplied by the signal fed into the transistors M1-M4 and the output obtained is a differential output. This circuit is characterized with respect to parameters shown in Table 1 and the result is compared with the result of circuit shown in Figure 7 after characterizing it with respect to the same parameters.
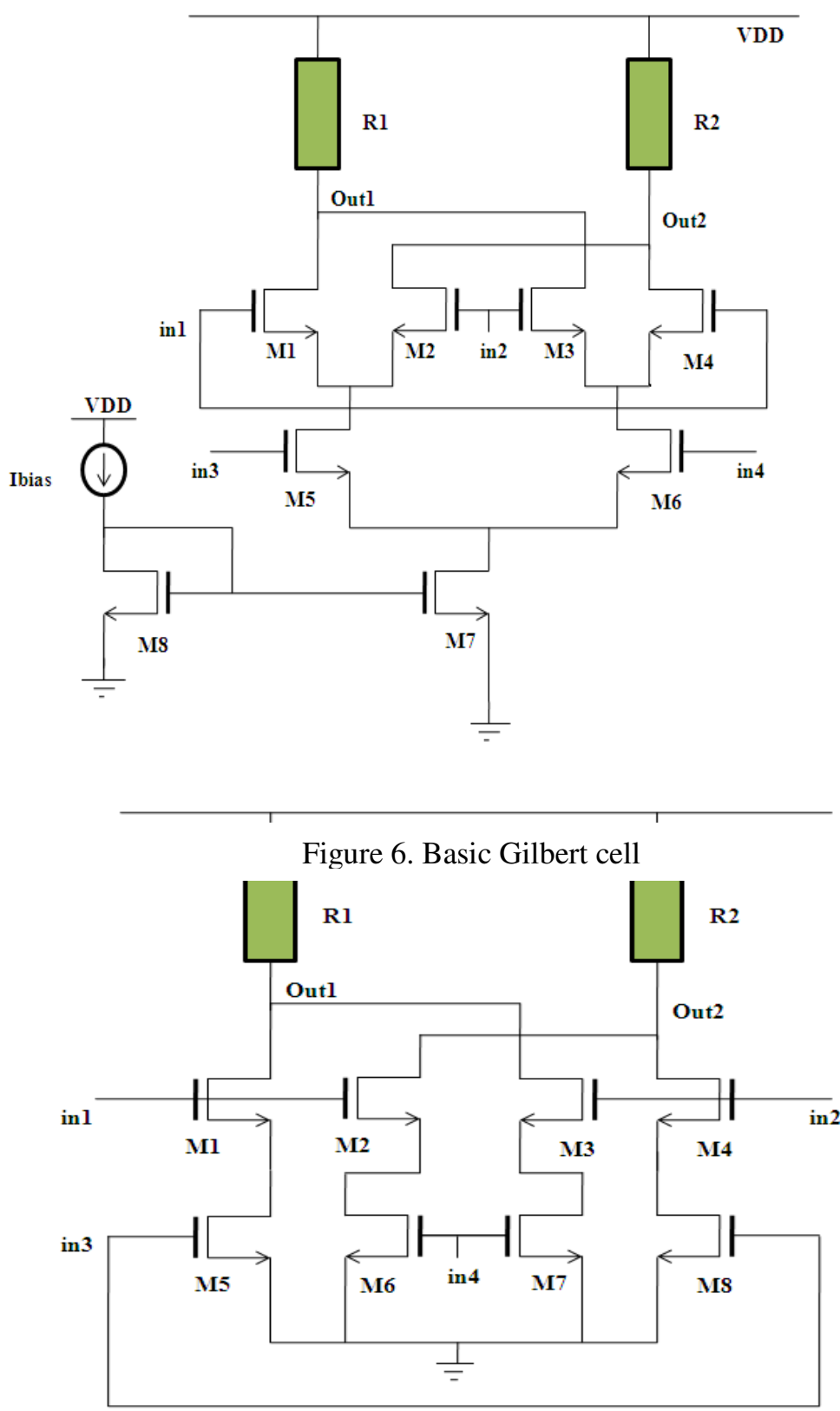

Figure 7. Fully differential four quadrant multiplier 
International Journal of VLSI design \& Communication Systems (VLSICS) Vol.3, No.5, October 2012

Table 2. Circuit Elements

\begin{tabular}{lcc}
\hline \hline Parameter Name & Basic Gilbert cell & $\begin{array}{c}\text { Fully Differential four } \\
\text { quadrant multiplier }\end{array}$ \\
\hline R1 & $70 \mathrm{k}$ & $70 \mathrm{k}$ \\
R2 & $70 \mathrm{k}$ & $70 \mathrm{k}$ \\
Ibias & $14 \mu \mathrm{A}$ & - \\
\hline Device Name & W/L & W/L \\
\hline M1 & 4 & 8 \\
M2 & 4 & 8 \\
M3 & 4 & 8 \\
M4 & 4 & 8 \\
M5 & 8 & 8 \\
M6 & 8 & 8 \\
M7 & 16 & 8 \\
M8 & 4 & 8 \\
\hline \hline
\end{tabular}

\section{SimULATION RESULTS AND}

PART A: The simulation results for the basic multiplier are discussed next. Each parameter is numbered for clarity of the overall characterization.

1. Transient analysis for the basic multiplier which is in figure 6 is done. The output is as shown in figure 8 .

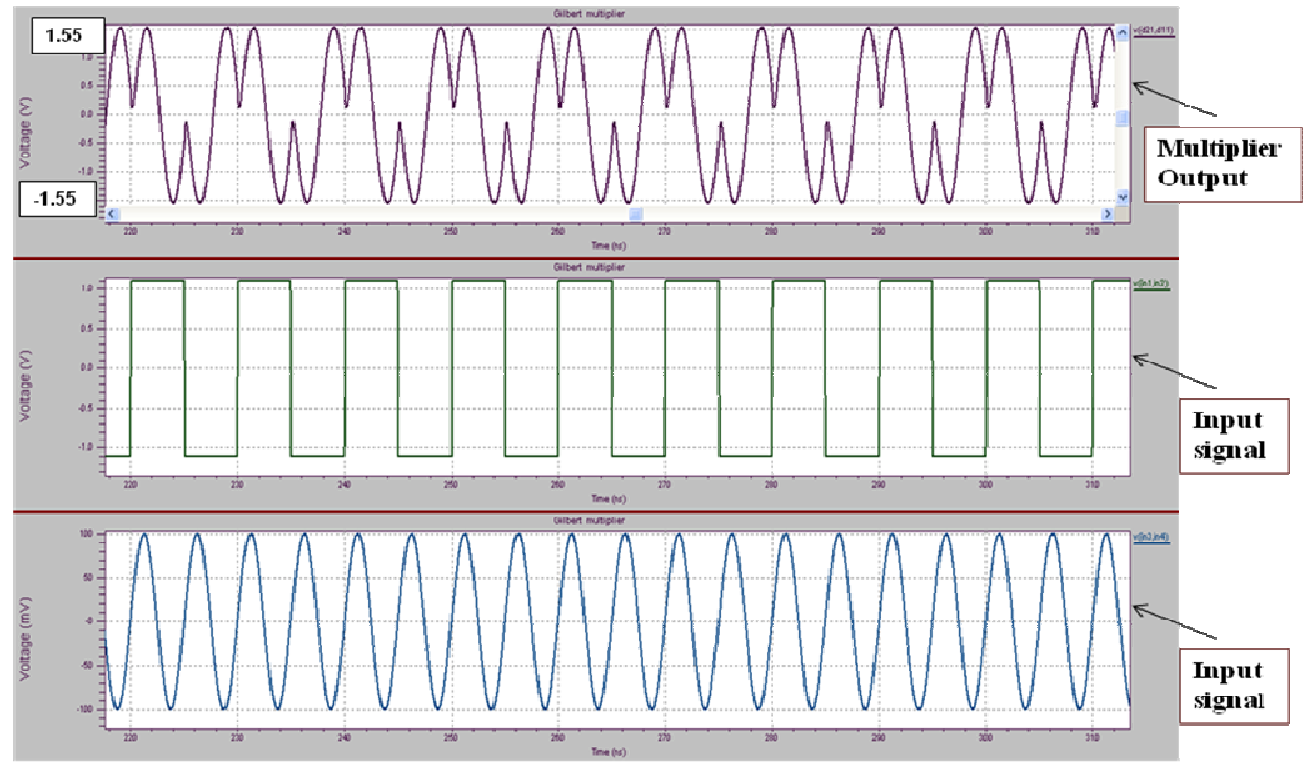

Figure 8.Transient Analysis of the Basic Gilbert cell multiplier 
International Journal of VLSI design \& Communication Systems (VLSICS) Vol.3, No.5, October 2012

The multiplier output from the simulation result in figure 8 is $1.55 \mathrm{v}$.

This approximately equals to the output value got from equation 19.

Hence Conversion Gain $=20 \log ($ vout/vin $)$

$$
=23.80 \mathrm{~dB}
$$

2. Dynamic range $=20 \log (\mathrm{vmax} / \mathrm{vmin})$

$$
=187.23 \mathrm{~dB}
$$

Where vmax and vmin are maximum and minimum values of voltages given to test the output of the multiplier.

3. Noise spectral density $\boldsymbol{N}_{\mathbf{0}}$ is the noise power per unit of bandwidth; that is, it is the power spectral density of the noise which has a dimension of power/frequency.

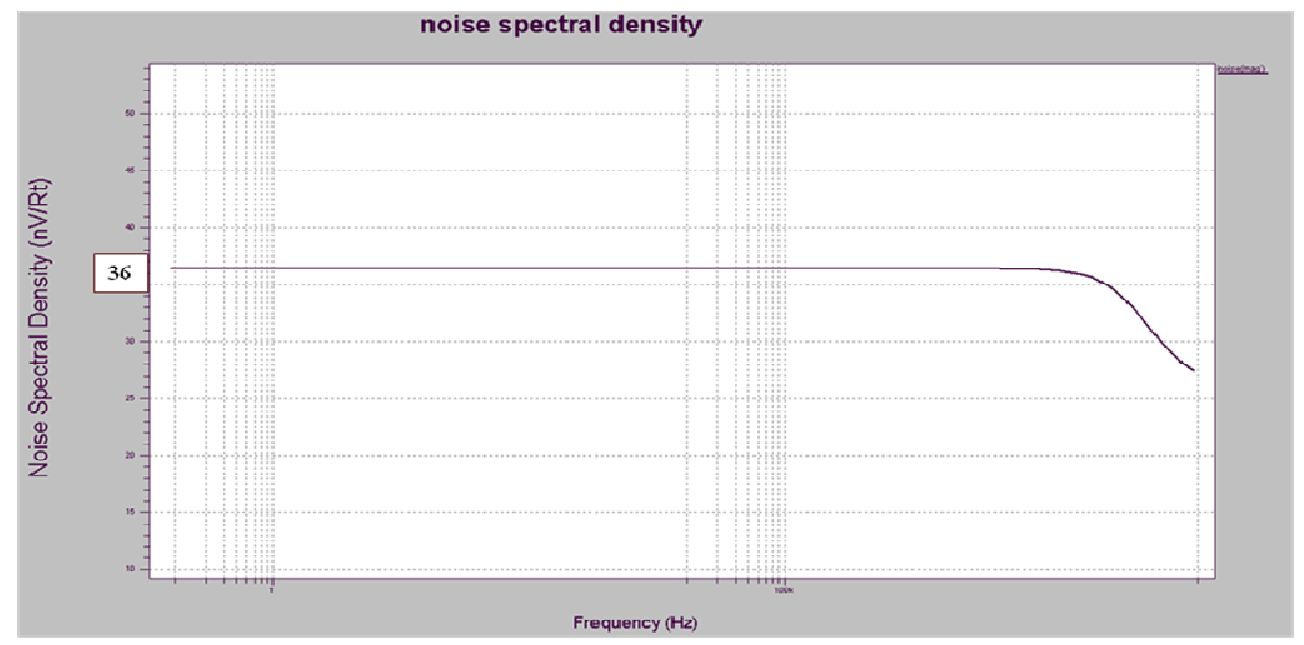

Figure 9. Noise spectral density of basic Gilbert cell multiplier

From figure 9, the noise spectral density is $36 \eta \mathrm{v} / \mathrm{Rt}$.

4. The power consumption of the circuit is $325 \mu \mathrm{W}$.

5. Total Harmonic Distortion, or THD is an amplifier or pre-amplifier specification that compares the output signal of the amplifier with the input signal and measures the level differences in harmonic frequencies between the two. The difference is called total harmonic distortion. The maximum THD in percentage is $40.75 \%$ for an input voltage of $1.5 \mathrm{~V}$. The THD plot is as shown in the Figure 10. 
International Journal of VLSI design \& Communication Systems (VLSICS) Vol.3, No.5, October 2012

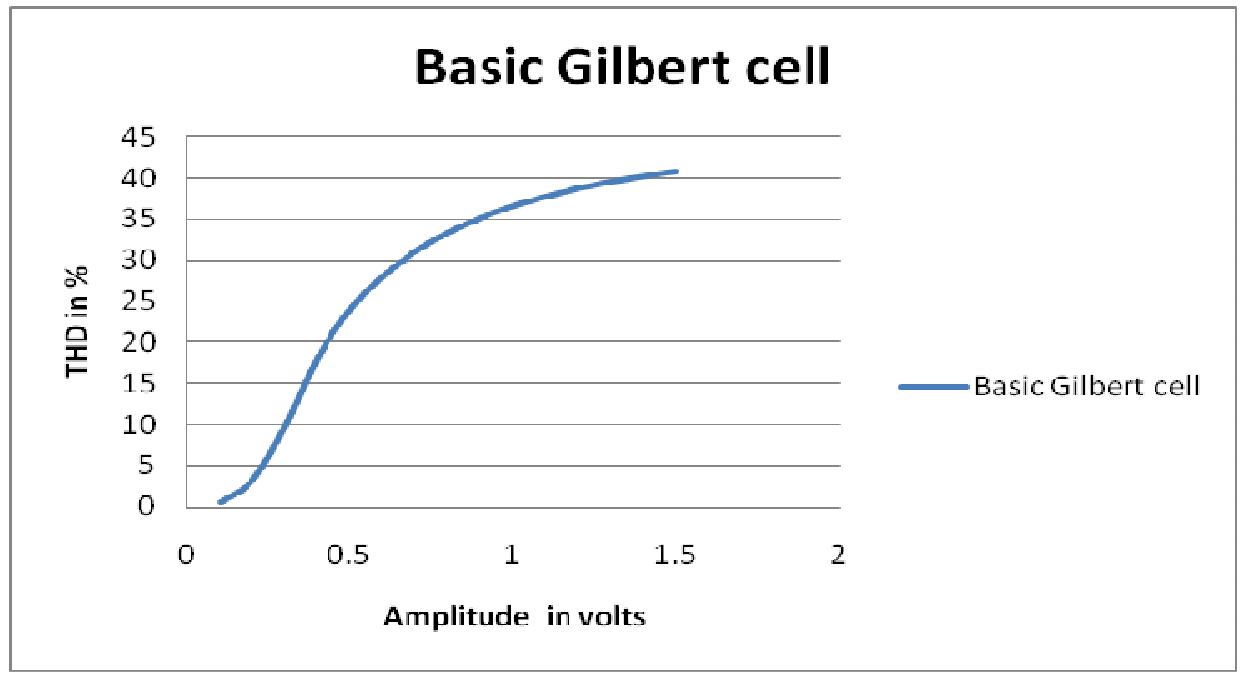

Figure 10. THD plot of basic Gilbert cell multiplier

PART B: The simulation results for the fully Differential four quadrant multiplier are discussed next. Each parameter is numbered for clarity of the overall characterization.

1. Transient analysis for the fully differential four quadrant multiplier is as shown in Figure 11.

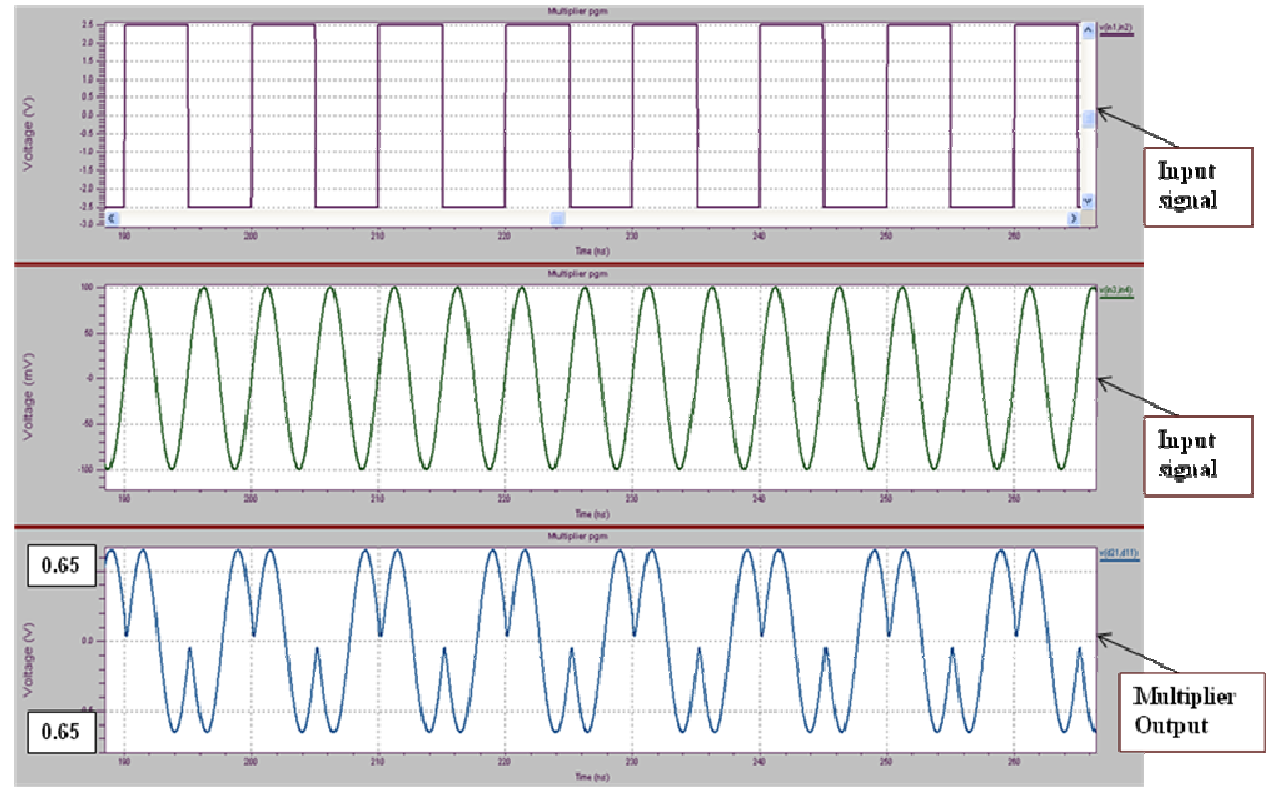

Figure 11. Fully Differential four quadrant multiplier

The fully differential four quadrant multiplier output is $0.65 \mathrm{v}$.

The conversion gain $=20 \log ($ vout $/ \mathrm{vin})=16.25 \mathrm{~dB}$.

2. Dynamic range $=20 \log (\operatorname{vmax} / \mathrm{vmin})$

$$
=195.56 \mathrm{~dB}
$$

Where vmax and vmin are maximum and minimum values of voltages given to test the output of the multiplier. 
International Journal of VLSI design \& Communication Systems (VLSICS) Vol.3, No.5, October 2012

3. The Noise spectral density is $590 \eta v / R t$ for the fully differential multiplier as shown in figure 12.

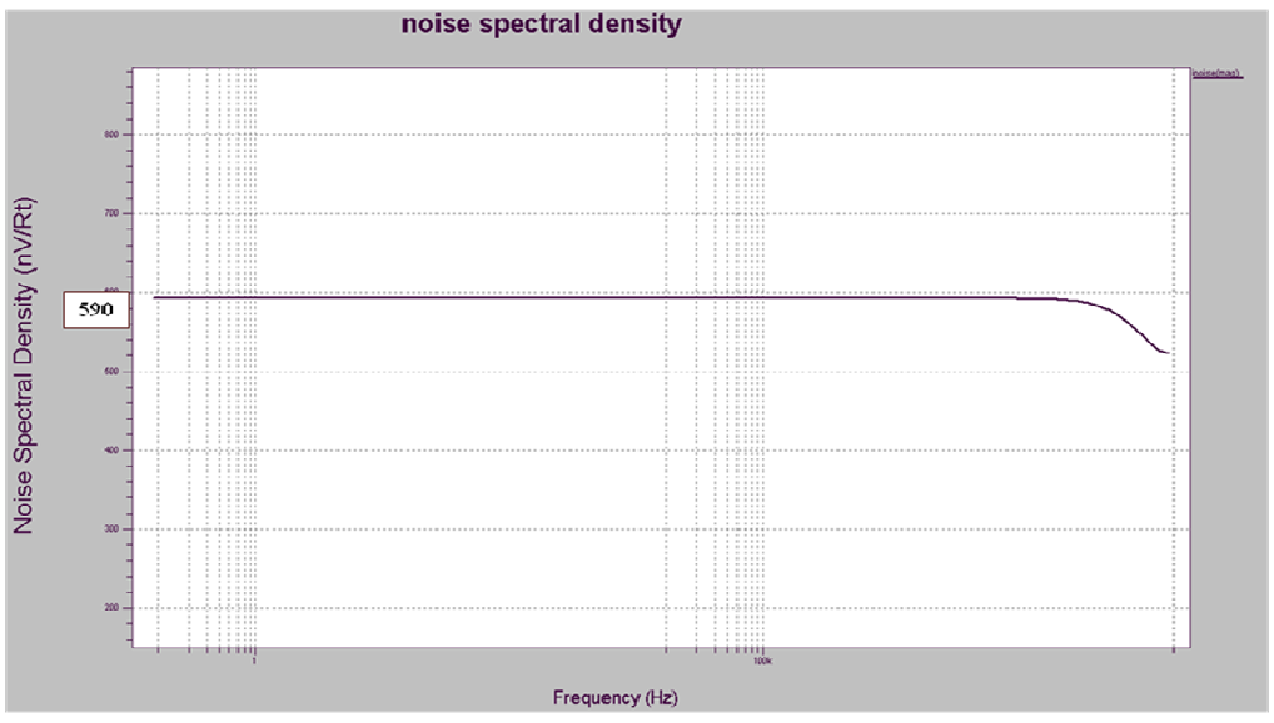

Figure 12. Noise spectral density of Fully Differential multiplier

4. Power consumption of the Fully Differential multiplier is $185 \mu \mathrm{W}$.

5. The maximum Total Harmonic Distortion in percentage is $18.06 \%$ for an input voltage of $1.5 \mathrm{~V}$. The THD plot is as shown in the Figure 13.

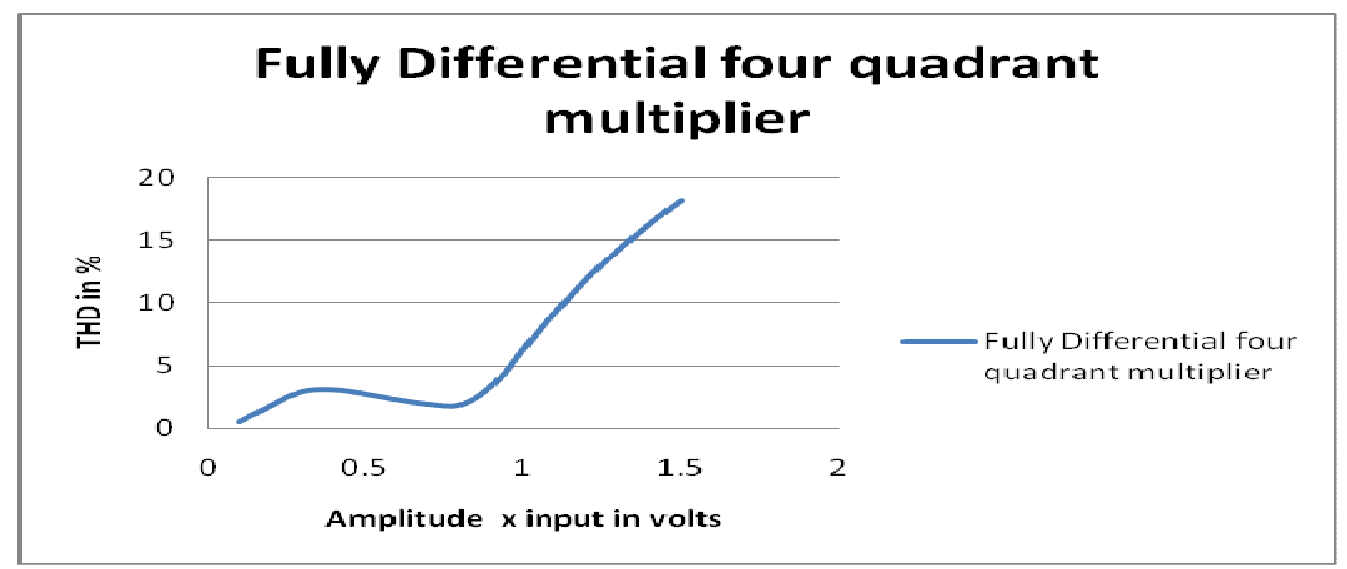

Figure 13. THD plot of Fully Differential four quadrant multiplier

Comparison of the results of Basic Gilbert cell multiplier and Fully differential four quadrant multiplier is given in the Table 3. 
International Journal of VLSI design \& Communication Systems (VLSICS) Vol.3, No.5, October 2012

Table 3. Comparison of The Two Multipliers

\begin{tabular}{|c|c|c|}
\hline Parameter Name & $\begin{array}{l}\text { Basic Gilbert cell } \\
\text { multiplier }\end{array}$ & $\begin{array}{l}\text { Fully Differential four } \\
\text { quadrant multiplier }\end{array}$ \\
\hline Supply Voltage & $5 \mathrm{~V}$ & $5 \mathrm{~V}$ \\
\hline Conversion gain & $24.17 \mathrm{~dB}$ & $16.25 \mathrm{~dB}$ \\
\hline Dynamic range & $187.23 \mathrm{~dB}$ & $195.56 \mathrm{~dB}$ \\
\hline $\begin{array}{l}\text { Noise } \\
\text { density }\end{array}$ & $36 \eta \mathrm{V} / \mathrm{Rt}$ & $590 \eta \mathrm{V} / \mathrm{Rt}$ \\
\hline $\begin{array}{l}\text { Frequency of } \\
\text { operation }\end{array}$ & $>100 \mathrm{MHz}$ & $>100 \mathrm{MHz}$ \\
\hline Power consumption & $325 \mu \mathrm{W}$ & $185 \mu \mathrm{W}$ \\
\hline $\begin{array}{lr}\text { Total harmonic } \\
\text { distortion } \\
1.5 \text { volt }\end{array}$ & $40.75 \%$ & $18.06 \%$ \\
\hline
\end{tabular}

This shows that the fully differential four quadrant multiplier is more linear and has less power consumption as compared to basic Gilbert cell multiplier.

\section{PART C: Comparison plots for power consumption and THD}

1. The power consumption for the Basic Gilbert cell multiplier and fully differential four quadrant multiplier are compared and is as shown in Figure 14.

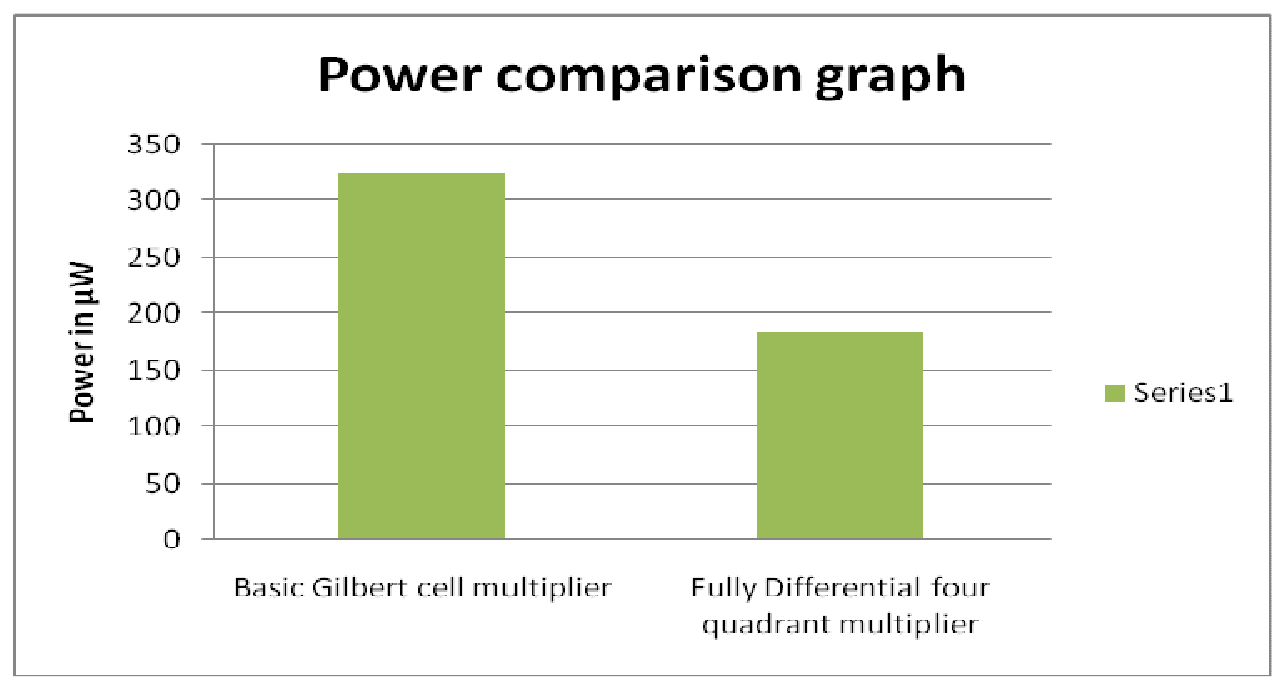

Figure 14. Comparison graph of power consumption of figures (6) and (7).

2. The total harmonic distortion for the Basic Gilbert cell multiplier and fully differential four quadrant multiplier are compared and is as shown in the Figure 15. 
International Journal of VLSI design \& Communication Systems (VLSICS) Vol.3, No.5, October 2012

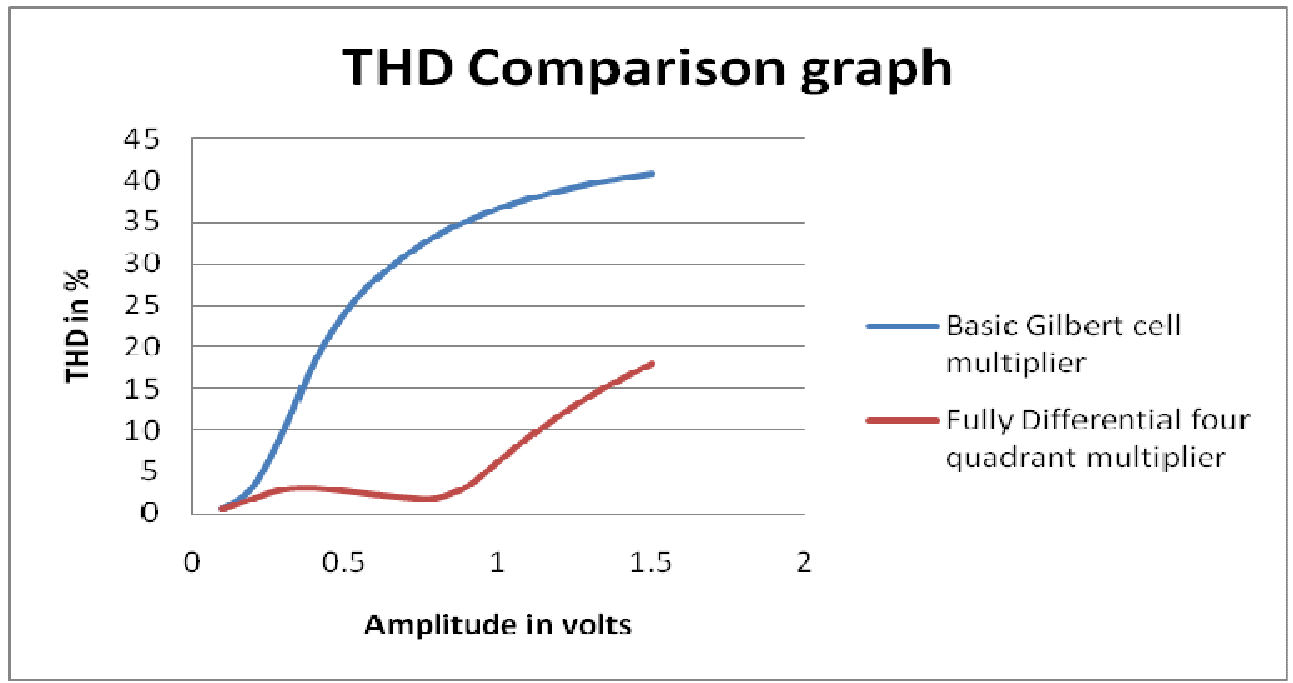

Figure 15. Comparison graph of THD of figures (6) and (7).

The goal of this work is to come with a multiplier architecture suitable for spread spectrum time domain reflectometry (SSTDR) [7]. SSTDR requires a multiplier with wide linear range and low power consumption. Fig 15 shows that fully differential four quadrant multiplier is much linear compared to Gilbert cell multiplier.

\section{LAYOUTS}

Layouts are drawn for the Basic Gilbert cell multiplier both with IO padframe and without IO padframe. In basic Gilbert cell multiplier, common centroid and fingering have been used and the layout is as shown in Figure 16.

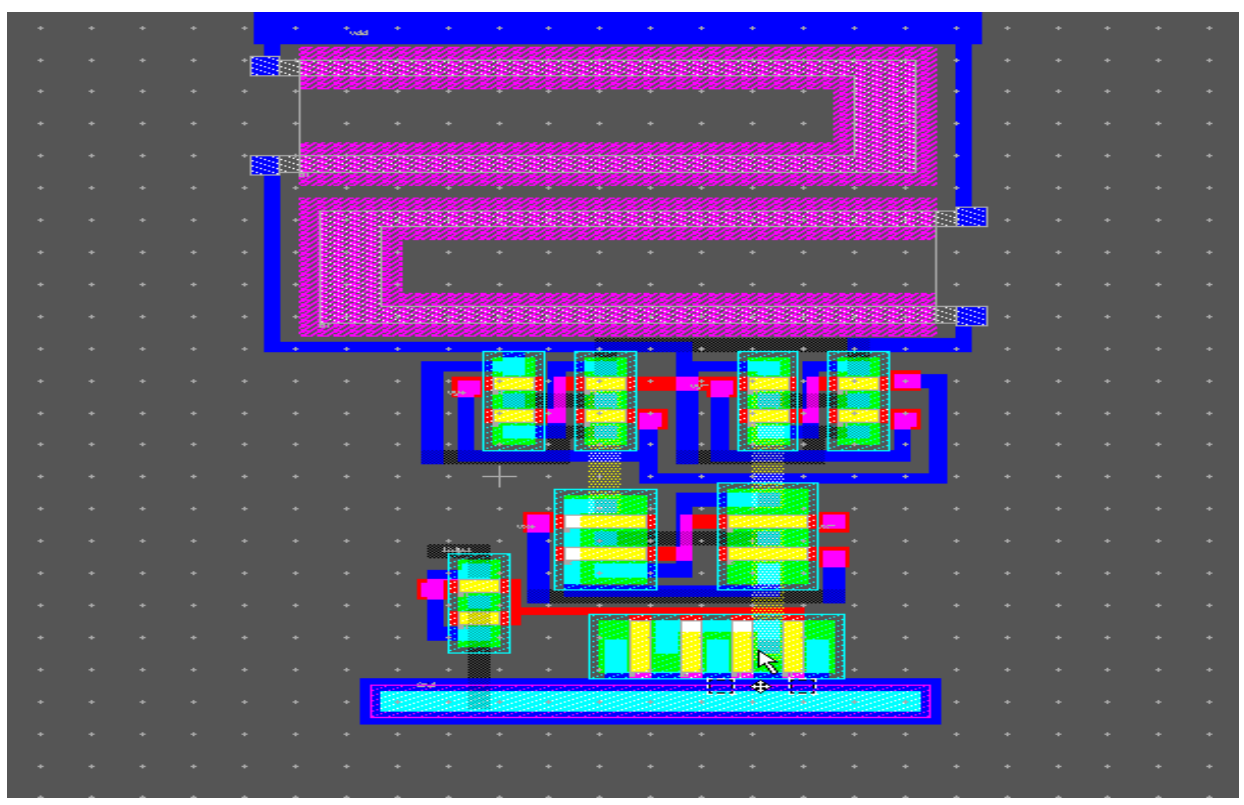

Figure 16. Common centroid layout of Basic Gilbert multiplier 
International Journal of VLSI design \& Communication Systems (VLSICS) Vol.3, No.5, October 2012

Area without IO pad $=\mathrm{L} * \mathrm{~W}$

$$
=66.6 \mu \mathrm{m} * 43.2 \mu \mathrm{m}=2877.12 \mu \mathrm{m}^{2}
$$

Basic Gilbert cell multiplier layout with IO pad frame is as shown in Figure 17.

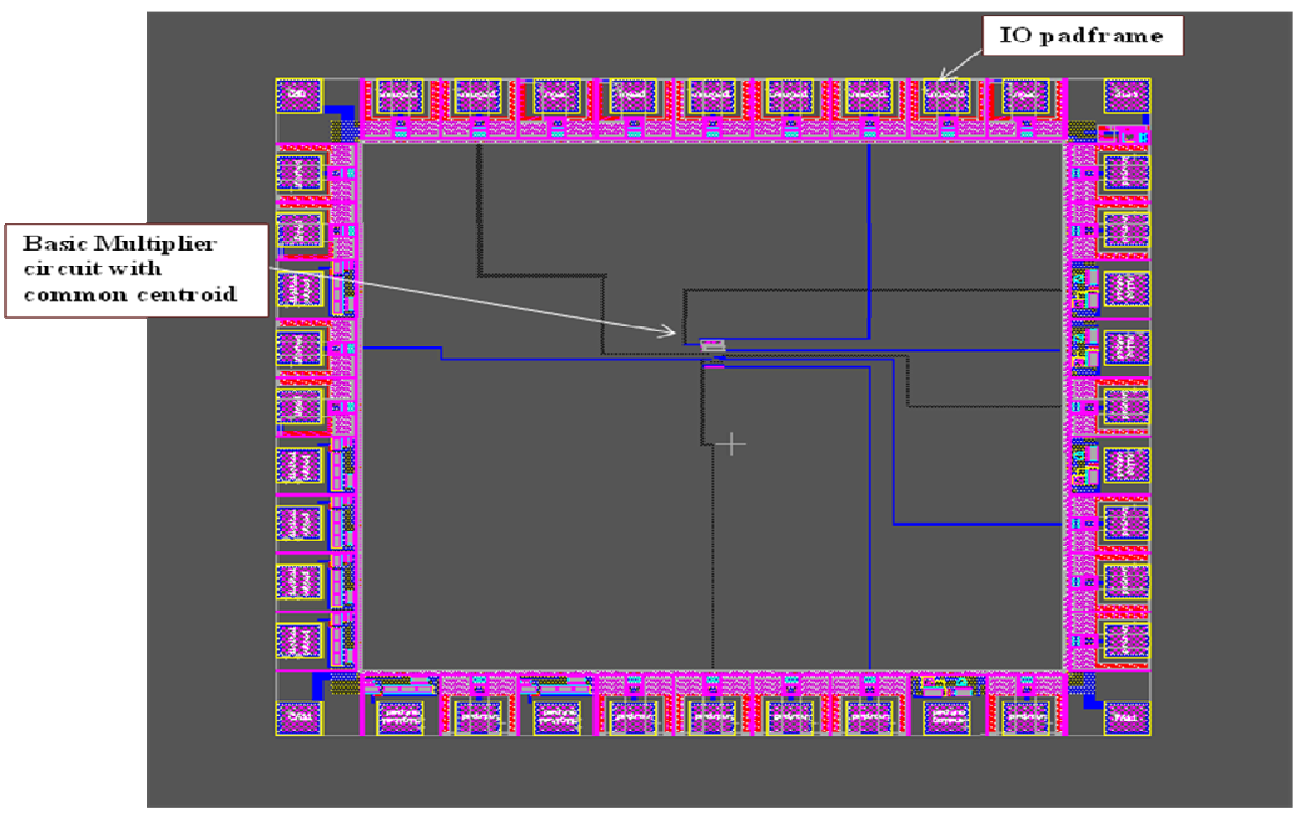

Figure 17. Basic Gilbert multiplier with IO padframe

Area with IO padframe $=1498.5 \mu \mathrm{m} * 1498.5 \mu \mathrm{m}$

Fully differential four quadrant multiplier layout without IO pad frame is as shown in Figure 18.

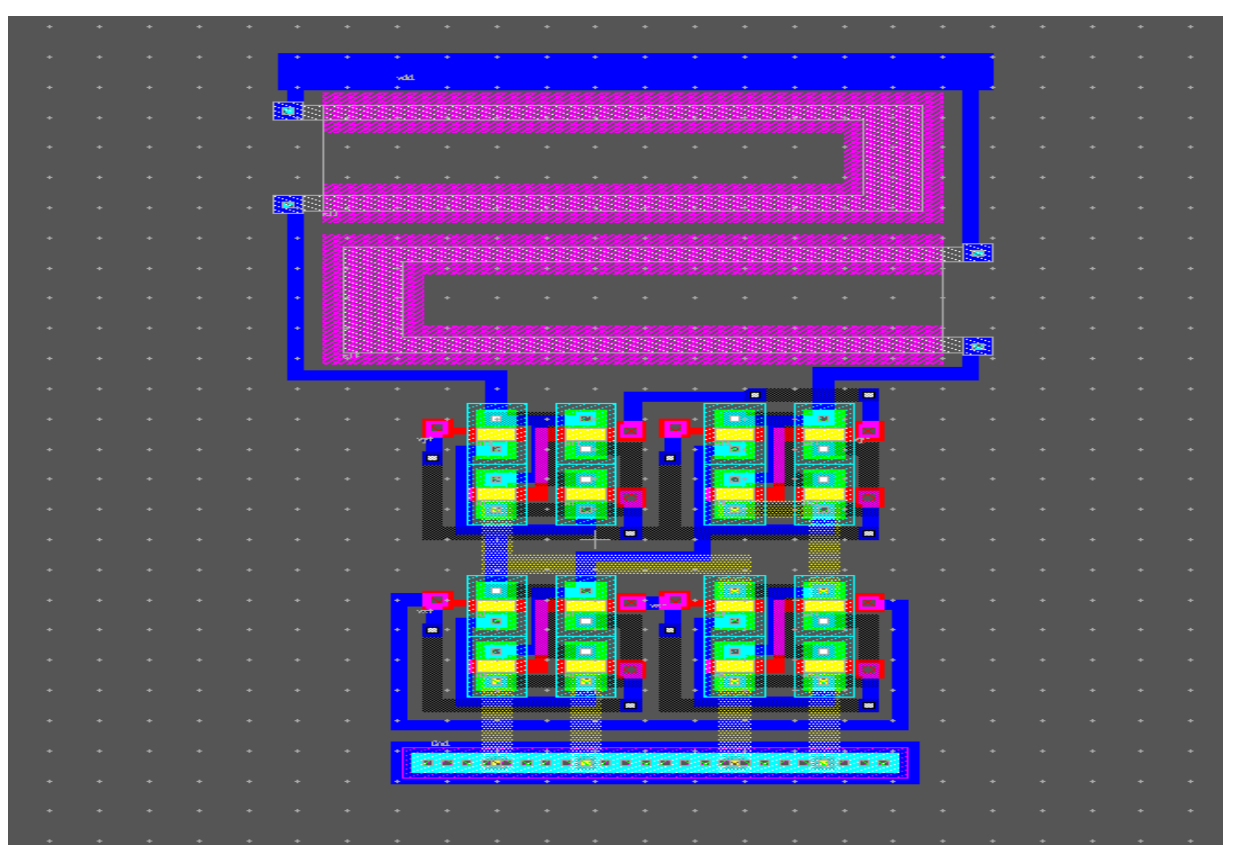

Figure 18. Common centroid layout of Fully differential four quadrant multiplier 
Area without IO pad $=\mathrm{L} * \mathrm{~W}$

$$
=72.6 \mu \mathrm{m} * 43.2 \mu \mathrm{m}=3158.1 \mu \mathrm{m}^{2}
$$

Fully differential four quadrant multiplier layout with IO pad frame is as shown in Figure 19.

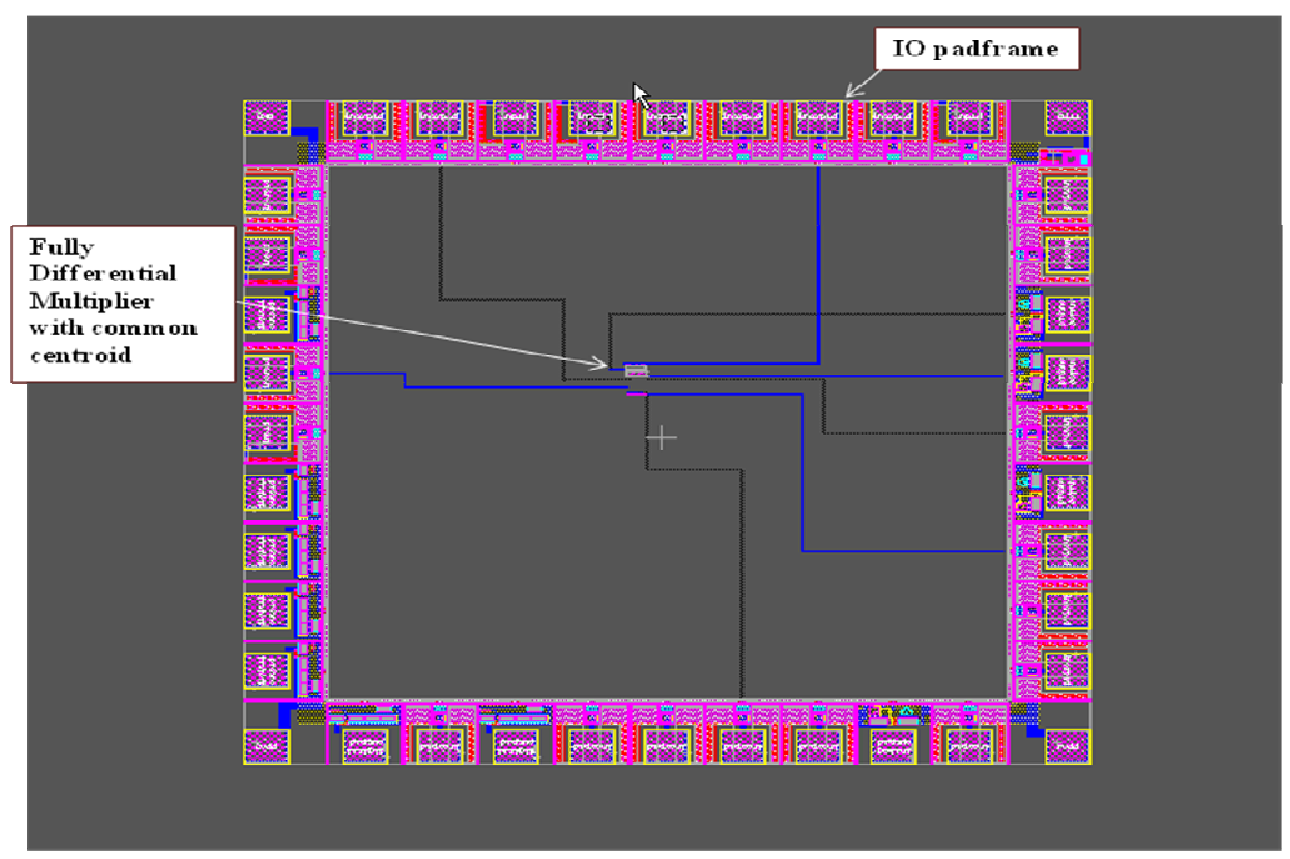

Figure 19. Fully differential four quadrant circuit with IO pad

For fully differential four quadrant multiplier, area with IO padframe is same as for the circuit shown in Figure 17.

\section{CONCLUSIONS}

In this work new multiplier architecture was compared to the widely used Gilbert cell multiplier. The goal of this work was to find a multiplier architecture with a wider linear range and lower power consumption. The Total Harmonic Distortion for the basic Gilbert cell multiplier and the fully differential four quadrant multiplier are $40.75 \%$ and $18.06 \%$ respectively. The power consumption for the basic Gilbert cell multiplier and the fully differential four quadrant multiplier are $325 \mu \mathrm{W}$ and $185 \mu \mathrm{W}$ respectively. Hence the proposed fully differential architecture has a lower Total Harmonic Distortion and power consumption than a Gilbert cell multiplier without much increase in chip area. Hence the fully differential four quadrant multiplier is better suited for SSTDR system compared to widely used Gilbert cell multiplier.

\section{REFERENCES}

[1] Analog multipliers, "MT-079 Tutorial”, www.analog.com/static/imported-files/tutorials/MT079.pdf.

[2] www.edaboard.com/thread95080.html

[3] J.P. Silver, "Gilbert Cell Mixer Design Tutorial", www.rfic.co.uk

[4] Gunhee Han, Sanchez Sinencio.E, (Dec 1998) "CMOS Transconductance Multipliers: A Tutorial", IEEE circuits and system society, vol 45

[5] B.Gilbert, (Dec.1968) "A precision four-quadrant multiplier with subnanosecond response," IEEE J. Solid-State Circuits, vol. SC-3, pp. 353-365.

[6] (Dec. 1974) "A high-performance monolithic multiplier using active feedback," IEEE J. Solid-State Circuits, vol. SC-9, pp. 364-373. 
[7] Chirag R. Sharma, Cynthia Furse and Reid R. Harrison, (Jan 2007 ) "Low-Power STDR CMOS Sensor for Locating Faults in Aging Aircraft Wiring”, IEEE Sensors Journal, vol. 7, no.1.

[8] J.Silva-Mart'inez and E. S'anchez-Sinencio, (May 1986 ), “Analogue OTA multiplier without input voltage swing restrictions, and temperature compensated”, Electron. Lett., vol. 22, pp. 599-600.

[9] E.S'anchez-Sinencio, J. Ram’irez-Angulo, B. Linares-Barranco, and A. Rodr'́rguez-V'azquez, (Dec. 1989 ) "Operational transconductance amplifier-based nonlinear function syntheses", IEEE J. SolidState Circuits, vol. 24.

[10] Behzad Razavi, (2002) "Design of analog CMOS integrated circuits", Tata McGraw hill.

[11] T.Enomoto and M. A. Yasumoto, "Integrated MOS four-quadrant analog multiplier using switched capacitor technology for analog signal processor IC's," IEEE J. Solid-State Circuits, vol. SC-20, pp. 852-859, Aug. 1985.

[12] Z.Zhang, X. Dong, and Z. Zhang, "A single D-FET 4QAM with SC technology," IEEE Trans. Circuits Syst., vol. 35, pp. 1551-1552, Dec. 1988.

[13] O.Changyue, C. Peng, and X. Yizhong, "Study of switched capacitor multiplier," in Int. Conf. Circuits Syst., China, June 1991, pp. 234-237.

[14] M.Ismail, R. Brannen, S. Takagi, R. Khan, O. Aaserud, N. Fujii, and N. Khachab, "A configurable CMOS multiplier/divider for analog VLSI," in Proc. IEEE Int. Symp. Circuits and Syst., May 1993, pp. 1085-1088.

[15] A.L. Coban and P. E. Allen, "Low-voltage CMOS transconductance cell based on parallel operation of triode and saturation transconductors," Electron. Lett., vol. 30, pp. 1124-1126, July 1994.

[16] “Low-voltage four-quadrant analogue CMOS multiplier," Electron.Lett., vol. 30, pp. 1044-1045, June 1994.

[17] “A 1.5 V four quadrant analog multiplier," in Proc. 37th Midwest Symp. Circuits and Syst., Lafayette , Aug. 1994, vol. 1, pp. 117-120.

[18] A.L.Coban, P. E. Allen, and X. Shi, "Low-voltage analog IC design in CMOS technology," IEEE Trans. Circuits Syst. I, vol. 42, pp. 955-958, Nov. 1995.

[19] J. L. Pennock, "CMOS triode transconductor for continuous-time active integrated filters," Electron. Lett., vol. 21, pp. 817-818, Aug. 1985.

[20] N. Khachab and M. Ismail, "MOS multiplier divider cell for analog VLSI," Electron. Lett., vol. 25, pp. 1550-1552, Nov. 1989.

[21] "A nonlinear CMOS analog cell for VLSI signal and information processing," IEEE J. Solid-State Circuits, vol. 26, pp. 1689-1694, Nov. 1991.

[22] S. Huang and M. Ismail, "CMOS multiplier design using the differential difference amplifier," in Proc. IEEE Midwest Symp. Circuits and Syst., Aug. 1993, pp. 1366-1368.

[23] C. Kim and S. Park, "New four-quadrant CMOS analogue multiplier," Electron. Lett., vol. 23, pp. 1268-1270, Nov. 1987.

[24] Z. Wang, "A four-transistor four-quadrant analog multiplier using MOS transistors operating in the saturation region,” IEEE Trans. Instrum. Meas., vol. 42, pp. 75-77, Feb. 1993.

[25] K. Kimura, "Analysis of "An MOS four-quadrant analog multiplier using simple two-input squaring circuits with source followers," IEEE Transactions Circuits Syst. I, vol. 41, pp. 72-75, Jan. 1994.

[26] Z. Hong and H. Melchior, "Four-quadrant CMOS analog multiplier," Electron. Lett., vol. 20, pp. 1015-1016, Nov. 1984.

[27] Z. Hong and H. Melchior, "Four-quadrant CMOS analog multiplier with resistors," Electron. Lett., vol. 21, pp. 531-532, June 1985.

[28] J. Ram'irez-Angulo, "Yet another low-voltage four quadrant analog CMOS multiplier," in Proc. IEEE Midwest Symposium Circuits and Syst., Aug. 1995. 
International Journal of VLSI design \& Communication Systems (VLSICS) Vol.3, No.5, October 2012

\section{Authors}

Nandini A S was born on $4^{\text {th }}$ November, 1987 in Bangalore. Nandini A S completed her Bachelor of Engineering in Telecommunication Engineering from Vivekananda Institute of Technology, Bangalore, Karnataka, India in 2009 and currently pursuing Master of Technology from Nitte Meenakshi Institute of Technology, Bangalore, Karnataka, India in VLSI Design and Embedded Systems.

Sowmya Madhavan was born on $26^{\text {th }}$ May, 1983 in Bangalore. Sowmya Madhavan completed her Bachelor of Engineering in Telecommunication Engineering from Vivekananda Institute of Technology, Bangalore, Karnataka, India in 2001 and Master of Technology from AMC College of Engineering, Bangalore, Karnataka, India in digital electronics and communication. She is currently pursuing her $\mathrm{PhD}$ under Visvesvaraya Institute of Technology in low power VLSI design.

Chirag R. Sharma was born on $1^{\text {st }}$ November, 1979. Chirag $R$ Sharma received the B.E. degree in electrical engineering from the Maharaja Sayajirao University, Baroda, India, in 2001, and the M.S. degree in electrical and computer engineering from Utah State University, Logan, in 2003. He also received the Ph.D. degree in electrical engineering at the University of Utah, Salt Lake City in 2009.His current research interests are analog and mixed-signal CMOS circuit design, CMOS sensors, and reflectometry techniques for locating intermittent faults on aircraft wiring.
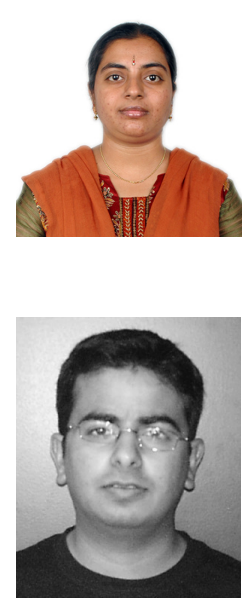